OPEN ACCESS

Edited by:

Mario Barreto,

Sapienza University of Rome, Italy

Reviewed by:

Hyo-Bin Kim,

Inje University Sanggye Paik Hospital,

South Korea

Michael David Shields,

Queen's University Belfast,

United Kingdom

${ }^{*}$ Correspondence:

Francesco Chiarelli

chiarelli@unich.it

orcid.org/0000-0002-3724-1495

Specialty section:

This article was submitted to

Pediatric Pulmonology,

a section of the journal

Frontiers in Pediatrics

Received: 30 November 2020 Accepted: 30 April 2021

Published: 25 May 2021

Citation:

Di Filippo P, Giannini C, Attanasi M, Dodi G, Scaparrotta A, Petrosino MI,

Di Pillo S and Chiarelli F (2021)

Pulmonary Outcomes in Children Born Extremely and Very Preterm at 11

Years of Age.

Front. Pediatr. 9:635503.

doi: 10.3389/fped.2021.635503

\section{Pulmonary Outcomes in Children Born Extremely and Very Preterm at 11 Years of Age}

\author{
Paola Di Filippo ${ }^{1,2}$, Cosimo Giannini ${ }^{1}$, Marina Attanasi ${ }^{2}$, Giulia Dodi ${ }^{1,2}$, \\ Alessandra Scaparrotta ${ }^{1,2}$, Marianna Immacolata Petrosino ${ }^{1,2}$, Sabrina Di Pillo ${ }^{2}$ and \\ Francesco Chiarelli ${ }^{\text {* }}$ \\ ${ }^{1}$ Department of Pediatrics, University of Chieti, Chieti, Italy, ${ }^{2}$ Pediatric Allergy and Respiratory Unit, Department of Pediatrics, \\ University of Chieti, Chieti, Italy
}

Background: There is increasing evidence of prematurity being a risk factor for long-term respiratory outcomes regardless the presence of bronchopulmonary dysplasia (BPD).

Aim: To assess the effect of prematurity on respiratory outcomes in children born $\leq 32$ weeks of gestational age at 11 years of age.

Materials and Methods: Fifty five ex-preterm children $(\leq 32$ weeks of gestational age), born in Chieti between January 1, 2006 and December 31, 2007, performed lung function and diffusing capacity test (DLCO) at 11 years of age. Furthermore, allergy evaluation by skin prick test (SPT), eosinophil blood count and assessment of eosinophilic airways inflammation by exhaled nitric oxide (FeNO) were performed. The ex-preterm group was compared to an age- and sex-matched group of term children.

Results: No difference for atopic and respiratory medical history was found between ex-preterm children and term controls, except for preschool wheezing that resulted more frequent in ex-preterm children. No difference neither in school-aged asthma frequency nor in lung function assessment at 11 years of age was found between the two groups. Lower DLCO values in ex-preterm children compared to term controls regardless the presence of BPD were found; furthermore, we showed a positive association between DLCO and gestational age. Eosinophil blood count, positive SPTs and FeNO values were similar between the two groups.

Conclusions: Diffusing lung capacity was decreased in ex-preterm children at 11 years of age in the absence of lung function impairment and eosinophil airway inflammation, suggesting a non-eosinophilic pattern underlying pulmonary alterations. It could be desirable to include the diffusing capacity assessment in follow-up evaluation of all ex-preterm children.

Keywords: prematurity, bronchopulmonar dysplasia, diffusing capacity for carbon monoxide, diffusing capacity for lung carbon monoxide, preschool wheezing 


\section{INTRODUCTION}

Neonatal intensive care reached extraordinary improvements during the last three decades. Antenatal corticosteroids in high risk pregnancies, postnatal surfactant replacement therapy and implementation of noninvasive ventilation techniques drastically reduced neonatal mortality and morbidity $(1,2)$.

However, a large proportion of children born preterm still develop long-term respiratory complications (3). Although pulmonary morbidity often improves during growth, in the majority of children with bronchopulmonary dysplasia (BPD), a subset of children still reports respiratory symptoms during childhood and adolescence (4). These complications affect not only subjects with BPD but even ex-preterm children without BPD (3).

The improved survival rate in infants born at very early gestational ages and a better management of neonatal respiratory distress led to a new pattern of lung injury. "Old" BPD was characterized by inflammation, airway smooth muscle hypertrophy, emphysema and parenchymal fibrosis due to high oxygen concentration and high ventilation pressures. The main cause of "new" BPD is the alveolar development arrest, which leads to reparative processes, impaired alveolarization with fewer and dysmorphic capillaries, despite a less evidence of emphysema, fibrosis and airway changes $(5,6)$. This new entity affects only infants born very preterm $(1,3)$ and it is still not clear whether the new BPD is associated with different long-term respiratory outcomes (3).

To date, most studies on long-term lung function focused on outcomes in BPD patients, while there is increasing evidence of prematurity per se being a risk factor for respiratory problems, even without BPD. Furthermore, efforts to compare the long-term respiratory outcomes of ex-preterm children with and without BPD are affected by relevant difficulties, and particularly the lack of shared definition (6) and of homogeneous populations.

The aim of the study was to assess the effect of prematurity on respiratory outcomes in children born $\leq 32$ weeks of gestational age compared to full-term controls at 11 years of age. Secondary aims were: (1) to evaluate the frequency of the respiratory symptoms in ex-preterm children; (2) to verify the role of the atopy and eosinophilic airway inflammation in their lung function.

\section{MATERIALS AND METHODS}

\section{Study Population}

The study was performed at the Pediatric Allergy and Respiratory Center, University Hospital of Chieti, Italy. The study population

Abbreviations: BPD, bronchopulmonary dysplasia; DLCO, diffusing capacity of the lung for carbon monoxide; SPT, skin prick test; FeNO, fractional exhaled nitric oxide; BMI; body mass index; ATS, American thoracic society; ERS, European respiratory society; $\mathrm{FEV}_{1}$, FVC, forced expiratory volume in the first second; forced vital capacity; $\mathrm{FEF}_{25-75}$, forced expiratory flow at the $25-75 \%$ of the pulmonary volume; TLC, total lung capacity; sRaw, specific airways resistances; RV, residual volume; SD, standard deviation; GLI-2012, global lung function initiative; LLN, lower limit of normal; COPD, chronic obstructive pulmonary disease. included all survived ex-preterm children born $\leq 32$ weeks of gestational age between January 1, 2006 and December 31, 2007 and admitted to the Neonatal Intensive Care Unit of Chieti (Figure 1). Perinatal and neonatal information were assessed by consulting their medical records.

School-aged ex-preterm children were asked to participate to our cross-sectional study between May 2017 and May 2018. Children with severe mental disability and/or tetraplegia were excluded. Asthma and atopy were not exclusion criteria.

The diagnosis of BPD was based on the oxygen need for 28 days and additional oxygen or ventilation requirements at 36 weeks' postmenstrual age (6).

An age- and sex-matched group of classmate for each expreterm child was sought. Classmates were excluded if they were born earlier than $<37$ weeks of gestational age. The presence of asthma and atopy was not an exclusion criterion. Controls recruitment was continued until 1:1 ratio was reached.

An accurate medical personal and family history was collected by a pediatric pulmonologist at follow-up visit. Current asthma was defined as physician-diagnosed asthma, obtained by parental questionnaire at age of 11 years, with a positive history of either wheezing or medication in the past 12 months. Preschool wheezing and school-aged asthma were defined as physicianasthma diagnosed until 5 years and from 5 to 10 years of age respectively.

A clinical evaluation including the anthropometric parameters (height, weight, BMI) and pubertal stage was performed at follow-up visit. A venous blood sampling for the eosinophil count, skin prick test for the allergic status, flow/volume curve and plethysmography for the lung function, fractional exhaled nitric oxide (FeNO) measurement for the airway inflammation were obtained at 11 years of age.

Written consent was taken from parents of the subjects. The follow-up study was approved by the Ethical Committee of University of Chieti.

\section{Measurement of Lung Function}

At the follow-up visit, all participants were in stable clinical condition without any acute respiratory symptoms in the previous 2 weeks.

Lung function was assessed in the Pediatric Allergy and Respiratory Clinic of the Department of Pediatrics of Chieti by flow/volume curves (using spirometer Master Screen; Viasys GmbH-Erich Jaeger, Hoechberg, Germany). They were made in the standing position using a nose clip. Until three consecutive technically acceptable curves were achieved according to ATS/ERS guidelines (7). The main spirometric parameters included were: forced expiratory volume in 1 second $\left(\mathrm{FEV}_{1}\right)$, forced vital capacity (FVC), the ratio $\mathrm{FEV}_{1} / \mathrm{FVC}$, forced expiratory flows between 25 and $75 \%$ of the FVC $\left(\mathrm{FEF}_{75}, \mathrm{FEF}_{25-75}\right)$. Total Lung Capacity (TLC), specific airways resistances (sRaw) and residual volume (RV) were measured using standardized body plethysmography $\left(\mathrm{Vmax}^{\circledR}\right.$ Autobox V62J, Carefusion, Hoechberg, Germany).

Lung function evaluation was performed at least 3 times for each patient; the best spirometric measurements were considered for statistical calculations. The maximal tolerated variability for 


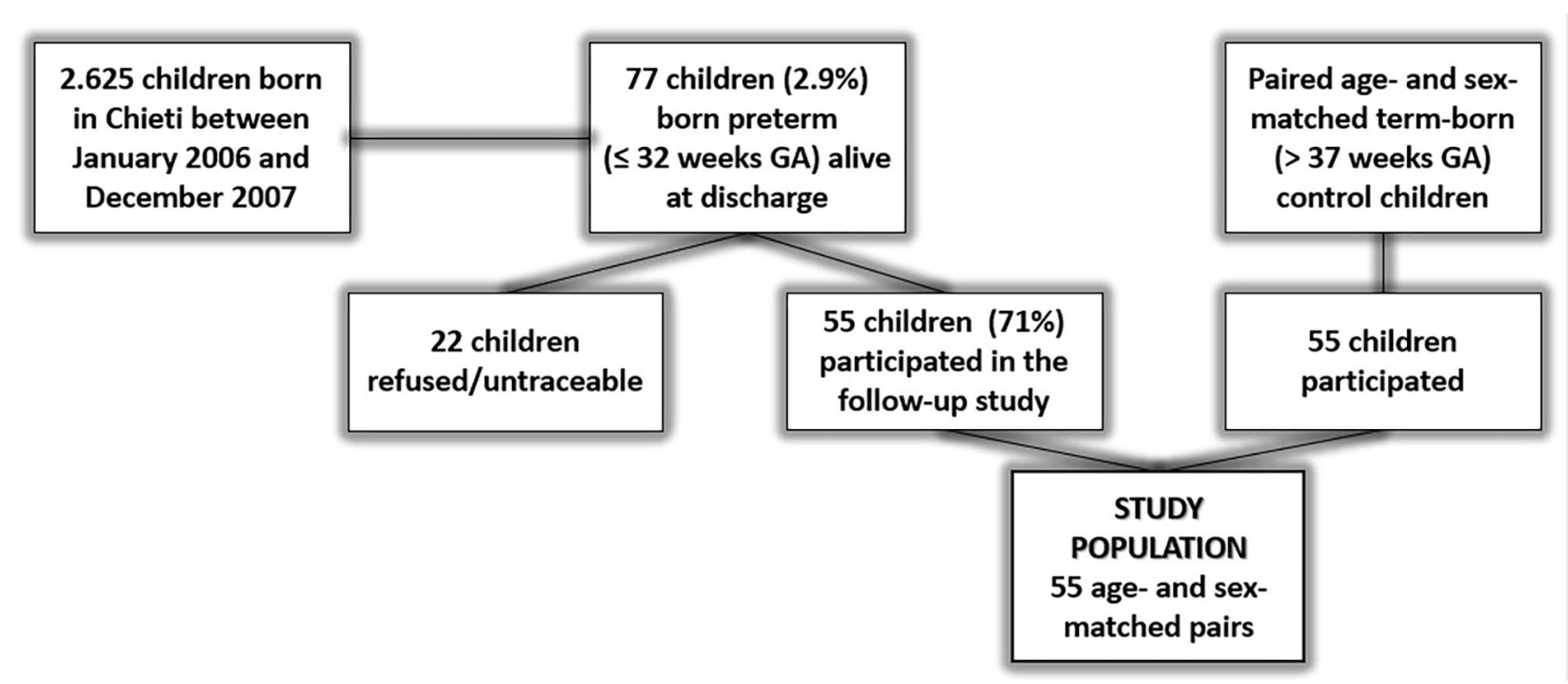

FIGURE 1| Flow-chart of the study. Children born in Chieti from January 1, 2006 to December 31, 2007 were 2,625. In the same period, infants born $\leq 32$ weeks of gestational age and alive at discharge were 77 (2.9\%). Of these 77 children, 55 accepted to be enrolled in the study; 22 refused or were untraceable.

the three lung function measurements was $<10 \%$, as referred by Pellegrino et al. (8).

Bronchodilator test was carried out $15 \mathrm{~min}$ after the administration of salbutamol $(200 \mathrm{mcg})$ using a spacer. An increase of at least $12 \%$ in $\mathrm{FEV}_{1}$ was considered significant for bronchial reversibility (8).

DLCO was measured with a standardized single breath technique $\left(\operatorname{Vmax}^{\circledR}\right.$ Autobox V62J, Carefusion, Hoechberg, Germany); nobody had a history of anemia. After the child established a stable breathing pattern he/she was instructed to exhale completely. The valve to the test gas was then opened and the patient took a full breath. The maneuver was considered reliable if the inspiratory time was $<4 \mathrm{~s}$ and the inhaled volume was at least $85 \%$ of the largest vital capacity. The patient then held his breath for $10 \pm 2 \mathrm{~s}$, maintaining near atmospheric pressure during the breath hold (performing neither a Valsalva nor Muller maneuver). DLCO maneuvers were repeated until at least two technically acceptable and reproducible tests were obtained (9).

\section{Respiratory Inflammation Marker}

FeNO was assessed with an on-line method using a single breath exhalation and a sensitive chemiluminescence assay (Ecomedics CLD 88), according to ATS-ERS (10). Patients performed an inspiration of eNO-free air via a mouthpiece immediately followed by full exhalation at a constant rate $(50 \mathrm{ml} / \mathrm{s})$ for at least $5 \mathrm{~s}$. The mean of three readings at the end of the expiration (plateau phase) was taken as the representative value for each measurement.

\section{Assessment of Allergy}

Allergic status was assessed by SPT for the most common food and respiratory allergens (Egg white and yolk, Milk, Cod, Tomato, Wheat, Peanut, Shrimp, Parietaria, Grass, Olive,
Cypress, Absinthe, Ambrosia, Dermatophagoides pteronyssinus and farinae, Cat and Dog dander, Alternaria alternate). Histamine $(10 \mathrm{mg} / \mathrm{ml})$ and saline were used as positive and negative controls respectively; diameters $\geq 3 \mathrm{~mm}$ were considered positive (11).

\section{STATISTICAL ANALYSIS}

Continuous data were presented as mean and standard deviation. Categorical data were presented as numbers and percentages.

Z-scores for DLCO, FEV $1, F V C, \mathrm{FEF}_{75}, \mathrm{FEF}_{25-75}$ and $\mathrm{FEV}_{1} / \mathrm{FVC}$ were derived using prediction equations from the Global Lung Function Initiative (GLI-2012) (12, 13) using specialized software (14). The lower limit of normal (LLN) was considered at the 5 th percentile of the $\mathrm{z}$-score distribution (13) which corresponded to -1.64 . Data on TLC, RV, sRaw were expressed as percentages of predicted for age, height, sex and ethnicity based on the Global Lungs Initiative (GLI) 2012 reference values (13).

Comparisons between ex-preterm children and term controls were performed by Mann Whitney U-test for continuous variables and Chi-squared test for categorical variables. In order to better characterize the independent effect of prematurity on the pulmonary function, ex-preterm participants were also divided according to the presence of BPD (ex-preterms with BPD and ex-preterms without BPD). Mann Whitney U-test was used to evaluate the differences between all ex-preterms and term controls, and between ex-preterms without BPD and term controls. Spearman correlation was performed to investigate the relationship between the main variables of interest and DLCO. A Backward linear regression analysis was performed using DLCO z-score as dependent variable and the main variables of interest (Gestational age, BMI, gender, birth weight, CPAP 
TABLE 1 | Main clinical characteristics of the two groups of the study population at birth and during the first 11 years of life.

\begin{tabular}{|c|c|c|c|}
\hline & $\begin{array}{l}\text { All preterms } \\
\qquad(N=55)\end{array}$ & $\begin{array}{l}\text { Term controls } \\
\qquad(N=55)\end{array}$ & $P$-values \\
\hline $\operatorname{Sex}(M / F)$ & $27 / 28$ & $27 / 28$ & \\
\hline \multicolumn{4}{|l|}{ Neonatal characteristics } \\
\hline Mother age at birth (years) & $30.8 \pm 5.4$ & $31.3 \pm 4.7$ & \\
\hline Gestational age (weeks) & $30.6 \pm 1.6$ & $38.4 \pm 1.4$ & \\
\hline Cesarean section (Yes/No; \%) & $54 / 1(98.2 \%)$ & 18/37 (32.7\%) & \\
\hline Birth weight (kg) & $1.43 \pm 0.4$ & $3.12 \pm 0.6$ & \\
\hline Birth length (cm) & $41.6 \pm 2.7$ & $49.6 \pm 2.1$ & \\
\hline Mechanical Ventilation (days) & $1.2 \pm 2.5$ & & \\
\hline CPAP (days) & $5.3 \pm 6.8$ & & \\
\hline Oxygen supplementation (days) & $7.6 \pm 9.6$ & & \\
\hline Hospital stay (days) & $45.5 \pm 19.6$ & $4.1 \pm 5.8$ & \\
\hline \multicolumn{4}{|l|}{ Prenatal and postnatal risk factors } \\
\hline Family history of asthma (Yes/No; \%) & $11 / 44(20.0 \%)$ & $12 / 43(21.8 \%)$ & 0.86 \\
\hline Family history of allergy (Yes/No; \%) & $19 / 36(34.5 \%)$ & 18/37 (32.7\%) & 0.84 \\
\hline In utero smoke exposure (Yes/No; \%) & $7 / 48(12.7 \%)$ & $5 / 50(9.1 \%)$ & 0.76 \\
\hline Passive smoking (Yes/No; \%) & 23/32 (41.8\%) & 18/37 (32.7\%) & 0.43 \\
\hline Pet keeping (Yes/No; \%) & $28 / 27(50.9 \%)$ & 20/35 (36.4\%) & 0.18 \\
\hline Breastfeeding (months) & $4.3 \pm 5.3$ & $10.2 \pm 6.9$ & $<0.001$ \\
\hline \multicolumn{4}{|l|}{ Medical history } \\
\hline Atopic dermatitis (Yes/No; \%) & $8 / 47$ (14.5\%) & $12 / 43(21.8 \%)$ & 0.46 \\
\hline Food allergy (Yes/No; \%) & 6/49 (10.9\%) & $4 / 51(7.3 \%)$ & 0.74 \\
\hline Bronchiolitis (Yes/No; \%) & $7 / 48(12.7 \%)$ & $5 / 50(9.1 \%)$ & 0.76 \\
\hline Allergic Rhinitis (Yes/No; \%) & $19 / 36(34.5 \%)$ & 23/32 (41.8\%) & 0.56 \\
\hline Pneumonia (Yes/No; \%) & $5 / 50(9.1 \%)$ & 6/49 (10.9\%) & 0.76 \\
\hline Urticaria (Yes/No; \%) & 6/49 (10.9\%) & $9 / 46(16.4 \%)$ & 0.58 \\
\hline Preschool wheezing (Yes/No; \%) & $15 / 40(27.3 \%)$ & $4 / 51(7.3 \%)$ & 0.01 \\
\hline School aged asthma (Yes/No; \%) & 6/49 (10.9\%) & $4 / 51(7.3 \%)$ & 0.74 \\
\hline Current asthma (Yes/No; \%) & $3 / 52(5.5 \%)$ & $4 / 51(7.3 \%)$ & 0.86 \\
\hline
\end{tabular}

Values are absolute numbers (percentages) for categorical data and mean \pm standard deviation for continuous variables.

$N$, numbers; CPAP, continuous positive airway pressure.

The statistical significance level is $p<0.05$ and it is indicated in bold.

duration, mechanical ventilation duration, breastfeeding) as independent variables.

The statistical significance level was $P<0.05$. Statistical analysis was performed using SPSS version 20.0.

\section{RESULTS}

Children born in Chieti from January 1, 2006 to December 31,2007 were 2,625 . In the same period, infants born $\leq 32$ weeks of gestational age and alive at discharge were 77 (2.9\%). Of these 77 children, 55 accepted to be enrolled in the study; 22 refused or were untraceable. All children were Caucasian. The flow-chart of the study is shown in the Figure 1. The main neonatal parameters were similar between preterm infants included in the study population and preterm infants not enrolled (Supplementary Material).

Neonatal and clinical characteristics of the study population in the previous 11 years of life are shown in Table 1. In terms of prenatal and postnatal risk factors (family history of asthma or allergy, in utero smoke exposure, passive smoke, pet keeping, time of weaning) no difference was found between ex-preterm children and term controls. Atopic and respiratory medical history (atopic dermatitis, food allergy, bronchiolitis, allergic rhinitis, pneumonia, urticaria) were similar between ex- preterm children and term controls, except for preschool wheezing prevalence. In fact, ex-preterm children presented more frequently pre-school wheezing compared to term controls (27.3 vs. $7.3 \% ; P=0.01$ ). No difference was found for school aged and current asthma.

The anthropometric, atopic and lung function data at 11 years of age are presented in Table 2. At the follow-up visit, all participants were pre-pubertal.

DLCO z-score was significantly lower in ex-preterm children than term controls $(-0.8 \pm 1.2$ vs. $0.4 \pm 1.1, P<0.001$; Figure 2$)$; noteworthy, we found a significant difference in DLCO between ex-preterm children without BPD and term children $(-0.6 \pm$ 1.1 vs. $0.4 \pm 1.1, P<0.001)$. A positive correlation between gestational age and DLCO z-score values was documented in ex-preterm children (Figure 3). The linear regression analysis confirmed the association between gestational age and DLCO z-score (Table 3).

Among ex-preterm children, 5 (9.1\%) had BPD (Table 2). Ex-preterm children with BPD showed worse specific airways resistances values and lower DLCO $\mathrm{z}$-score values compared to ex-preterm children without BPD (sRaw\%: $219.6 \pm 23.4$ vs. $184.4 \pm 48.9, P=0.02$; DLCO z-scores $-1.7 \pm 0.8$ vs. $-0.6 \pm$ $1.1, P=0.04$, respectively).

We also found lower DLCO z-score values in ex-preterm without BPD compared to term controls $(-0.7 \pm 1.2$ vs. $0.4 \pm$ $1.1, P<0.001)$, thus highlighting the effect of prematurity on alveolar-capillary membrane also without the presence of BPD.

Lung function expressed by flow/volume parameters $\left(\mathrm{FEV}_{1} \mathrm{Z}\right.$ score, FVC z-score, $\mathrm{FEV}_{1} / \mathrm{FVC}_{\mathrm{z}}$-score, $\mathrm{FEF}_{75}$ z-score, $\mathrm{FEF}_{25-75}$ $\mathrm{Z}$-score) was not significantly different between the two groups. Bronchodilator reversibility was not significantly different between the two groups. At plethysmography, sRaw\% and TLC\% were significantly different between ex-preterms and term controls $(187.7 \pm 48.1$ vs. $169.2 \pm 24.9, P=0.04$ and $98.5 \pm 14.9$ vs. $103.9 \pm 16.1, P=0.02$, respectively).

No difference in term of atopic characteristics (serum eosinophils, skin prick test and FeNO) were found between the ex-preterm children and term controls (Table 3 ).

\section{DISCUSSION}

In our study ex-preterm children reported higher frequency of preschool wheezing than term controls. These results are also confirmed in several studies (15-17) and in a large metaanalysis with 1.5 million children from six continents finding that prematurity was associated with a 1.7 -fold higher risk of childhood wheezing disorders (18).

In the past, the higher frequency of wheezing in all subjects born prematurely was interpreted as asthma. To date the mechanisms of airflow obstruction in subjects with a history 
TABLE 2 | Anthropometric, atopic, and lung function data at 11 years of the study population.

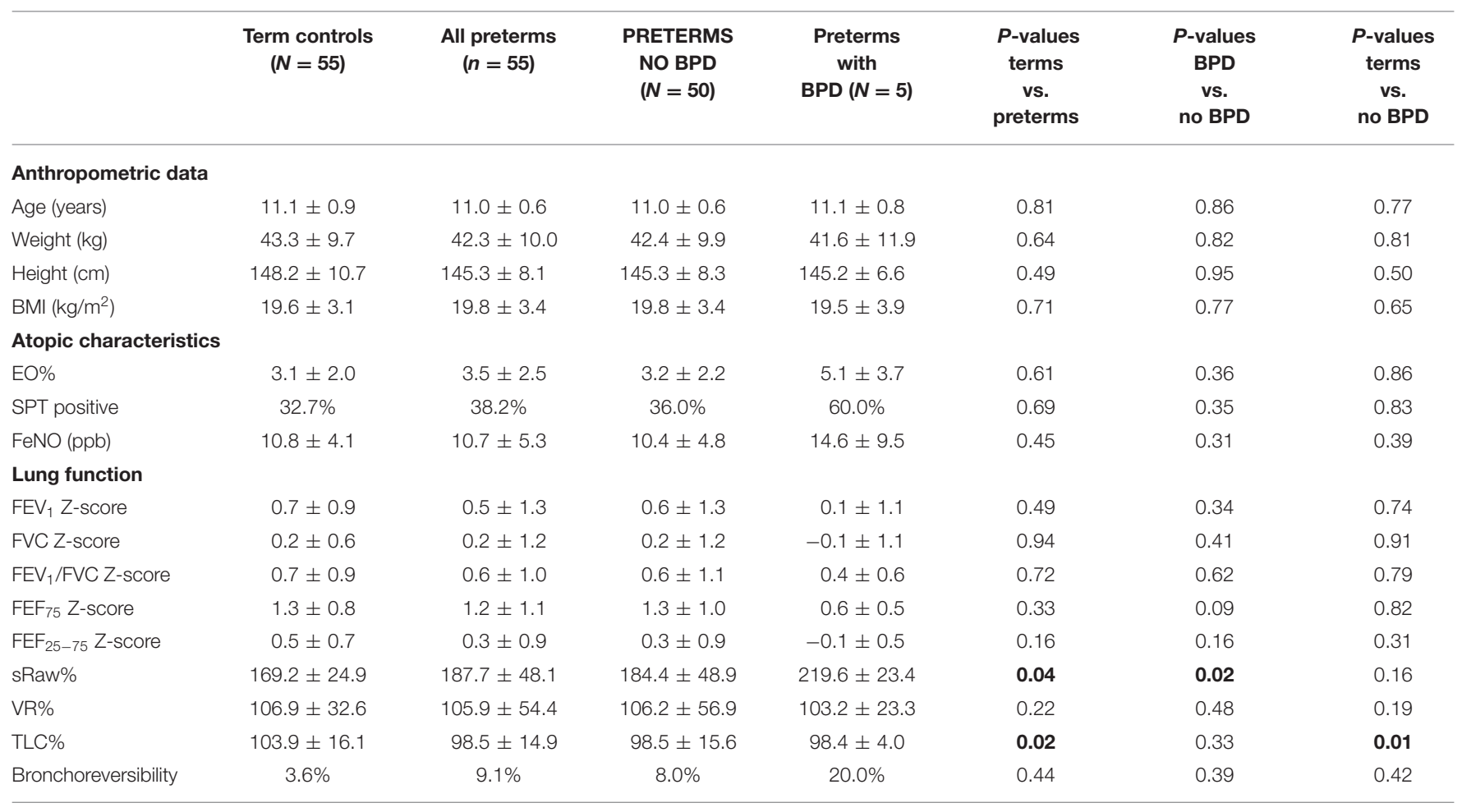

Values are percentages for categorical data and mean \pm standard deviation for continuous variables.

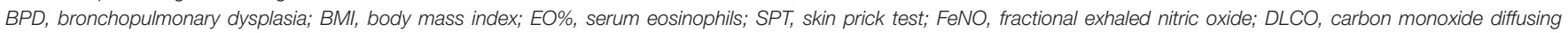

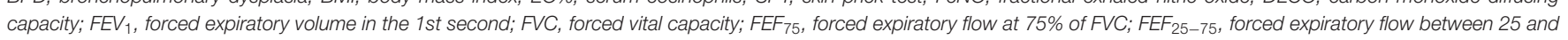
75\% of FVC; sRaw, specific airway resistance; VR, residual volume; TLC, total lung capacity.

The statistical significance level is $p<0.05$ and it is indicated in bold.

of prematurity are not entirely understood. Kennedy et al. (15) proposed that fewer alveoli and alveolar attachments in preterm lung causes more difficult opening of small airways during a period of rapid postnatal lung growth. This finding leads to an impaired airway growth and fixed airflow obstruction similar to Chronic Obstructive Pulmonary disease (COPD).

We found a normal lung function in ex-preterm children compared to controls at 11 years of age despite higher frequency of preschool wheezing. Scientific evidence is still conflicting regarding the persistence of impaired lung function in expreterm children. On one hand, a lot of studies showed lung function impairment in preterm children (19-21). On the other hand, several studies observed inconsistent association between birth weight and FEV1/FVC $(22,23)$. Kitchen et al. (24) found that lung function was similar in very low birth weight children compared to normal weight birth ones at 8 years of age, despite very low birth weight children suffered more frequently from wheezing in the first 2 years of life. In a recent study performed in preschool aged children, a similar lung function in mild BPD ex-preterm subjects compared to ex-preterm ones without BPD and term controls has been shown, suggesting that mild BPD might not lead to long-term respiratory consequences (21). The available conflicting findings might be partially explained by the small study sample size, the heterogeneity in the definition of BPD and in the lung function methods utilized, and the different age in which lung function was assessed in cross-sectional studies.
Few longitudinal studies were performed. A recent longitudinal study assessing lung function at different time points $(6,12,18$, and 24 months) found that lung function in preterm infants with mild to moderate BPD improved gradually (25).

To date several studies include adults with "old BPD" born before surfactant era and very few studies have evaluated lung function of ex-preterm adults with "new BPD." New interesting insights have been offered by a recent study including young adults born prematurely between 1987 and 1998. In this study authors found lower z- score $\mathrm{FEV}_{1} / \mathrm{FVC}, \mathrm{FEV}_{1}$, DLCO and lung density (quantified by CT scanning) in subjects with BPD than those without BPD. These parameters were above the lower limit of normal in 55\% of recruited subjects, suggesting recovery of lung function impairment in a reasonable percentage of survivors of BPD (26).

These recent findings suggest that ex-preterm children with early reduced lung function compared to term controls could improve lung function over time, especially in absence of BPD $(15,25,27)$. According to these findings, we speculate that the lung function was normal in our study population at 11 years of age probably because their lung function improved over time. However, higher percentage of ex-preterm children without BPD than ones with BPD could influence mean values of the lung function parameters.

Noteworthy, we showed that children born $\leq 32$ weeks of gestational age presented an impaired diffusing capacity 


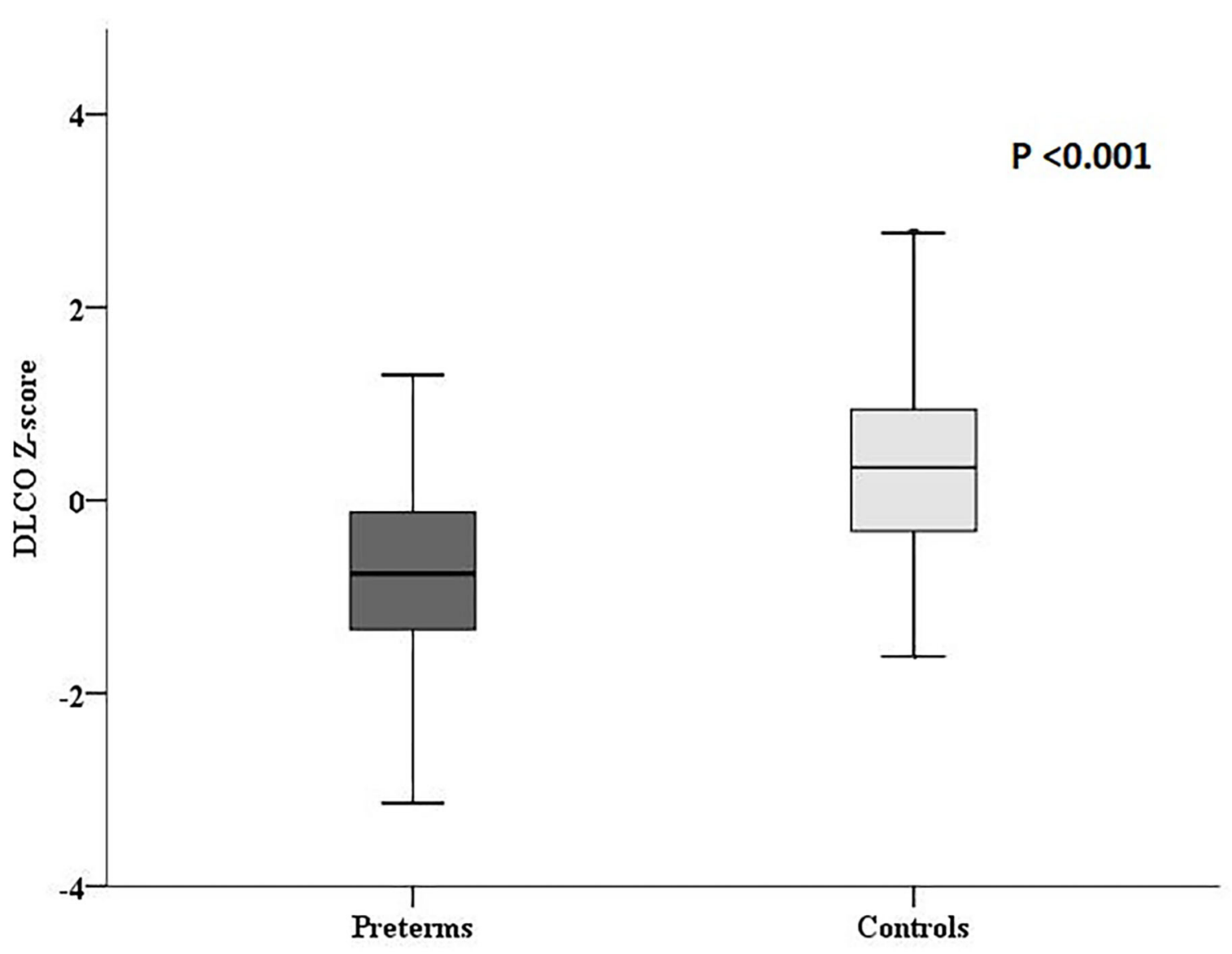

FIGURE 2 | DLCO z-scores in ex-preterm children and term controls at 11 years of age.
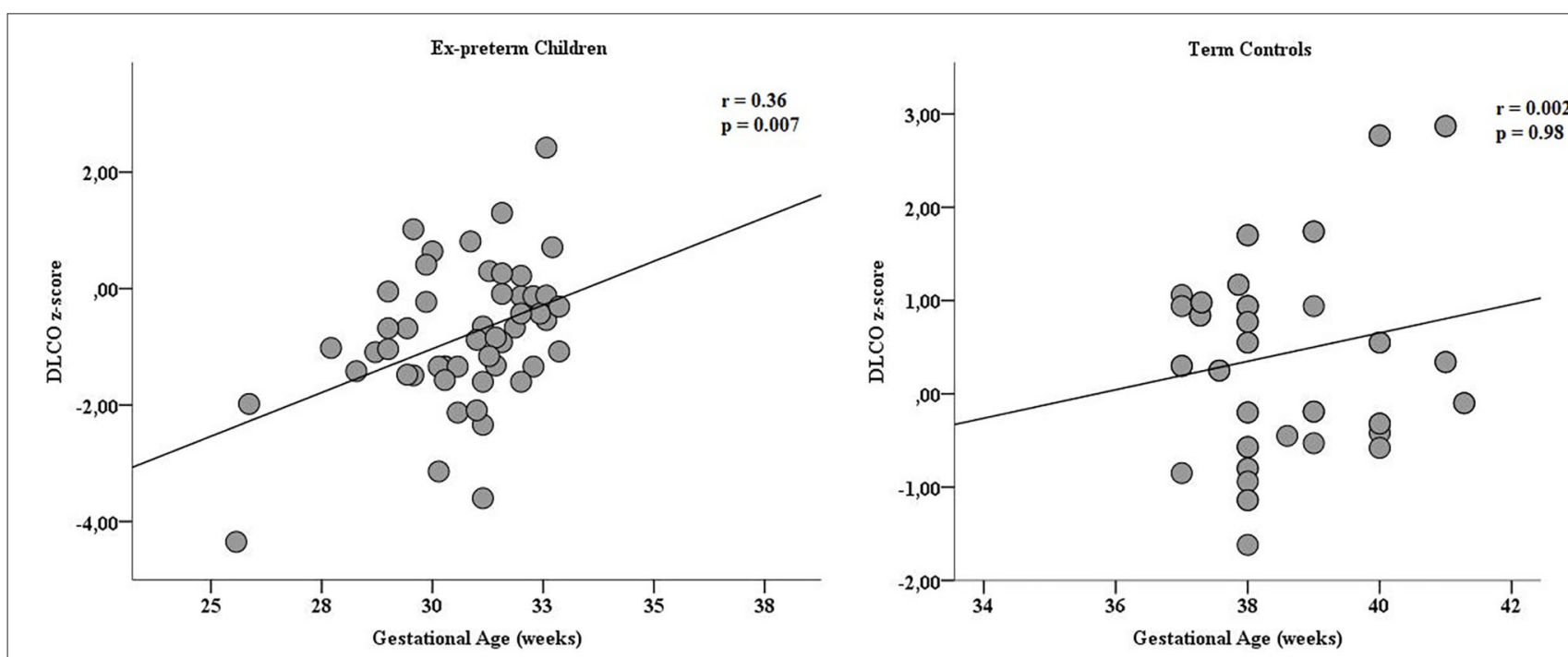

FIGURE 3 | Correlation of gestational age (expressed in weeks) and DLCO z-score in preterm children and term controls at 11 years of age. The positive correlation was found only in the preterm group. 
compared to full-term controls at 11 years of age. Lower DLCO $\mathrm{z}$-score values persisted in ex-preterm subjects without BPD compared to term controls, highlighting the effect of prematurity on alveolar-capillary membrane also without BPD.

DLCO is a compound measure, reflecting lung volume, surface area accessible for gas exchange, thickness of the alveolar capillary barrier and pulmonary capillary blood volume (28). We expected lower DLCO values in ex-preterm children than controls given that the alveolar-capillary membrane grows considerably between 22 and 32 weeks of gestational age (5). The disruption in alveolar and vascular growth in preterm subjects result in more simplified pulmonary acini and vascular structures (5), reducing the surface area for gas exchange, as confirmed in autopsy findings in preterm infants (29). The overall reduction in number of pulmonary capillaries with the remaining vessels being dysmorphic and far from the airspace surface result in thickened alveolar-capillary membrane (30).

Several studies found that DLCO is reduced by about $10 \%$ in subjects born preterm compared with subjects born at term (28, 31, 32); particularly, two studies evaluating extremely preterm children demonstrated ventilation inhomogeneity and gas transfer impairment in ex-preterm subjects at 11 years of age $(32,33)$.

Importantly, we showed a positive association between gestational age and DLCO in ex-preterm children, which persisted after adjusting for birth weight, CPAP duration, mechanical ventilation duration, breastfeeding, BMI and sex, suggesting an independent effect of prematurity on DLCO values. According to these findings, both Hakulinen et al. (31) and Um-Bergström et al. (34) demonstrated a disturbance of gas diffusion in presence of a normal lung function in ex-preterm young adults without previous diagnosis of BPD. In addition, as also suggested recently, in ex-preterm children the alteration of diffusing capacity at 10 years of age could be the hallmark of an underlying peripheral airway impairment (35).

FeNO values, SPT positivity and eosinophil blood count were similar in ex-preterm group compared to term controls. These findings might suggest that lung diffusing capacity is not induced by eosinophil airways inflammation and that airways inflammation is different in ex-preterm children compared to asthmatics children. A recent meta-analysis with 640 preterms and 4,005 term controls found no difference in FeNO levels between ex-preterm and term subjects and between ex-preterm subjects with and without Chronic Lung Disease (36). To date, several studies have shown no eosinophilic markers in ex preterm children $(35,37)$ suggesting an alternative inflammation pattern underlying wheezing and airway obstruction in expreterms subjects. Indeed BPD seems to be characterized by persistent neutrophilic airway inflammation and oxidative stress resembling inflammatory mechanisms of COPD (4).

The main strength of our study are the simultaneous assessment of lung function, diffusing capacity and airways eosinophilic inflammation providing a comprehensive respiratory evaluation of the participants. Secondly, our study include children born at high-resource tertiary hospital in the post-surfactant era with "new BPD" respect to several available studies on school aged children or teenagers including
TABLE 3 | Aassociation between the main variables of interest and DLCO by a multi stepwise linear regression analysis.

\begin{tabular}{lcc}
\hline & Regression coefficient & $\boldsymbol{P}$-value \\
\hline Gestational age & 0.52 & $\mathbf{0 . 0 0 0}$ \\
Birth weight $(\mathrm{kg})$ & 0.07 & 0.76 \\
Sex & 0.13 & 0.14 \\
Mechanical ventilation duration (days) & 0.11 & 0.25 \\
CPAP duration (days) & 0.17 & 0.12 \\
Breastfeeding duration (months) & 0.13 & 0.16 \\
Body mass index at follow-up visit $\left(\mathrm{kg} / \mathrm{m}^{2}\right)$ & 0.14 & 0.12 \\
\hline
\end{tabular}

CPAP, continuous positive airway pressure.

The statistical significance level is $p<0.05$ and it is indicated in bold.

subjects with "old BPD." Furthermore, spirometric and DLCO parameters were expressed as z-score according to the equation GLI-2012 (14), minimizing the different effects of age, sex, height and race. All measurements were performed by the same operator with expertise in lung function methods. Lastly, the presence of a control group supports the reliability of our findings.

The main limitation of our study are the cross-sectional analysis and the lack of lung function assessment in the first years of life when respiratory symptoms were present. However, we collected data about the previous 11 years of life (prenatal, perinatal and postnatal factors). Another important limitation was the small sample size of the study population, in particular of the preterms with BPD resulting in a very skewed comparison between preterm with and without BPD.

In conclusion, we found that ex-preterm children report more frequently preschool wheezing compared to term children. No significant difference in terms of frequency of school agedasthma and current asthma and in the lung function values between ex-preterm children and term controls at 11 years of age was found, suggesting a potential gradual clinical improvement over time in ex-preterm children. In addition, no significant difference was also found in eosinophilic airways inflammation and atopic characteristics between the two groups. Therefore, we postulate that the pathological mechanism and the underlying airways inflammation of chronic lung disease of prematurity could be inherently different from asthma $(38,39)$. Importantly, we showed a reduced diffusing capacity in ex-preterm children compared to full-term controls at 11 years of age. Further, longitudinal prospective studies with a larger sample size of "new BPD" children and with periodic evaluation of lung function from birth to adulthood are needed to better characterize lung function changes over time. However, our findings highlight the importance to follow-up ex-preterm children with a periodic lung function assessment which includes not only spirometry but also diffusing capacity testes.

\section{DATA AVAILABILITY STATEMENT}

The raw data supporting the conclusions of this article will be made available by the authors, without undue reservation. 


\section{ETHICS STATEMENT}

This study was approved by the Ethics Committee of the University of Chieti. A written informed consent to participate in this study was provided by the participants' legal guardian/next of kin.

\section{AUTHOR CONTRIBUTIONS}

PDF contacted and recruited patients at 11 years of age and wrote the manuscript. CG performed the statistical analysis.

\section{REFERENCES}

1. Ronkainen E, Dunder T, Peltoniemi O, Kaukola T, Marttila R, Hallman M. New BPD predicts lung function at school age: Follow-up study and meta-analysis. Pediatr Pulmonol. (2015) 50:1090-8. doi: 10.1002/ppul.23153

2. Jobe AH, Ikegami M. Lung development and function in preterm infants in the surfactant treatment era. Annu Rev Physiol. (2000) 62:82546. doi: 10.1146/annurev.physiol.62.1.825

3. Priante E, Moschino L, Mardegan V, Salvadori S, Baraldi E. Respiratory outcome after preterm birth: a long and difficult journey. Am J Perinatol. (2016) 33:1040-2. doi: 10.1055/s-0036-1586172

4. Carraro S, Filippone M, Da Dalt L, Ferraro V, Maretti M, Bressan S, et al. Bronchopulmonary dysplasia: the earliest and perhaps the longest lasting obstructive lung disease in humans. Early Hum Dev. (2013) 89:35. doi: 10.1016/j.earlhumdev.2013.07.015

5. Baker CD, Alvira CM. Disrupted lung development and bronchopulmonary dysplasia: opportunities for lung repair and regeneration. Curr Opin Pediatr. (2014) 26:306-14. doi: 10.1097/MOP.0000000000000095

6. Bancalari E, Jain D. Bronchopulmonary dysplasia: 50 years after the original description. Neonatology. (2019) 115:384-91. doi: 10.1159/000497422

7. Miller MR, Hankinson J, Brusasco V, Burgos F, Casaburi R, Coates A, et al. Standardisation of spirometry. Eur Respir J. (2005) 26:31938. doi: 10.1183/09031936.05.00034805

8. Pellegrino R, Viegi G, Brusasco V, Crapo RO, Burgos F, Casaburi R, et al. Interpretative strategies for lung function tests. Eur Respir J. (2005) 26:94868. doi: 10.1183/09031936.05.00035205

9. Graham BL, Brusasco V, Burgos F, Cooper BG, Jensen R, Kendrick A, et al. 2017 ERS/ATS standards for single-breath carbon monoxide uptake in the lung. Eur Respir J. (2017) 49:1600016. doi: 10.1183/13993003.00016-2016

10. American Thoracic Society; European Respiratory Society. ATS/ERS recommendations for standardized procedures for the online and offline measurement of exhaled lower respiratory nitric oxide and nasal nitric oxide, 2005. Am J Respir Crit Care Med. (2005) 15:171:912-30. doi: 10.1164/rccm.200406-710ST

11. van Kampen V, de Blay F, Folletti I, Kobierski P, Moscato G, Olivieri M, et al. EAACI position paper: skin prick testing in the diagnosis of occupational type I allergies. Allergy. (2013) 34:580-4. doi: 10.1111/all.12120

12. Stanojevic S, Graham BL, Cooper BG, Thompson BR, Carter KW, Francis RW, et al. Global Lung Function Initiative TLCO Working Group; Global Lung Initiative (GLI) TLCO. Official ERS technical standards: Global Lung Function Initiative reference values for the carbon monoxide transfer factor for Caucasians. Eur Respir J. (2017) 11:50. doi: 10.1183/13993003.00010-2017

13. Quanjer PH, Stanojevic S, Cole TJ, Baur X, Hall GL, Culver BH, et al. ERS Global Lung Function Initiative. Multi-ethnic reference values for spirometry for the 3-95 yr age range: the global lung function 2012 equations. Eur Respir J. (2012) 40:1324-43. doi: 10.1183/09031936.00080312

14. Quanjer PH, Stanojevic S, Cole TJ, Baur X, Hall GL, Culver $\mathrm{BH}$, et al. GLI-2012 Data Conversion Software. Available online at: www.lungfunction.org/tools.html (accessed July 4, 2018).

15. Kennedy JD. Lung Function outcome in children of premature birth. J Paediatr Child Health. (1999) 35:51621. doi: 10.1046/j.1440-1754.1999.00422.x
GD participated in the writing of the manuscript. AS analyzed neonatal records of patients. MIP participated to the recruitment of patients. MA, SDP, and FC revised the manuscript. All authors contributed to the article and approved the submitted version.

\section{SUPPLEMENTARY MATERIAL}

The Supplementary Material for this article can be found online at: https://www.frontiersin.org/articles/10.3389/fped. 2021.635503/full\#supplementary-material

16. Lawlor DA, Ebrahim S, Davey Smith G. Association of birth weight with adult lung function: findings from the British Women's Heart and Health Study and a meta-analysis. Thorax. (2005) 60: 851-8. doi: 10.1136/thx.2005. 042408

17. Gonçalves D de MM, Wandalsen GF, Scavacini AS, Lanza Fc, Goulart $\mathrm{AL}$, Solé $\mathrm{D}$, et al. Pulmonary function in former very low birth weight preterm infants in the first year of life. Respir Med. (2018) 136:837. doi: 10.1016/j.rmed.2018.02.004

18. Been J V, Lugtenberg MJ, Smets E, van Schayck CP, Kramer BW, Mommers $\mathrm{M}$, et al. Preterm birth and childhood wheezing disorders: a systematic review and meta-analysis. PLoS Med. (2014) 11: e1001596. doi: 10.1371/journal.pmed.1001596

19. Colin AA, McEvoy C, Castile RG. Respiratory morbidity and lung function in preterm infants of 32 to 36 weeks' gestational age. Pediatrics. (2010) 126:115-28. doi: 10.1542/peds.2009-1381

20. McGrath-Morrow SA, Ryan T, Riekert K, Lefton-Greif MA, Eakin M, Collaco JM. The impact of bronchopulmonary dysplasia on caregiver health related quality of life during the first 2 years of life. Pediatr Pulmonol. (2013) 48:57986. doi: $10.1002 /$ ppul.22687

21. Chang H-Y, Chang J-H, Chi H, Hsu C-H, Lin C-Y, Jim W-T et al. Reduced lung function at preschool age in survivors of very low birth weight preterm infants. Front Pediatr. (2020) 8:577673. doi: 10.3389/fped.2020.577673

22. Saad NJ, Patel J, Burney P, Minelli C. Birth weight and lung function in adulthood: a systematic review and meta-analysis. Ann Am Thorac Soc. (2017) 14:994-1004. doi: 10.1513/AnnalsATS.201609-746SR

23. He B, Kwok MK, Au Yeung SL, Lin SL, Leung JYY, Hui LL, et al. Birth weight and prematurity with lung function at $\sim 17.5$ years: "children of 1997 " birth cohort. Sci Rep. (2020) 10:341. doi: 10.1038/s41598-019-56086-7

24. Kitchen WH, Olinsky A, Doyle LW, Ford GW, Murton LJ, Callanan C, Slonim L. Respiratory health and lung function in 8-year-old children of very low birth weight: a cohort study. Pediatrics. (1992) 89:1151-8.

25. Lai SH, Chiang MC, Chu SM, Hsu JF, Yao TC, Tsai MH, et al. Evolution and determinants of lung function until late infancy among infants born preterm. Sci Rep. (2020) 10:490. doi: 10.1038/s41598-019-57359-x

26. Santema HY, Stolk J, Los M, Stoel BC, Tsonaka R, Merth IT Prediction of lung function and lung density of young adults who had bronchopulmonary dysplasia. ERJ Open Res. (2020) 6:00157-2020. doi: 10.1183/23120541.00157-2020

27. Jordan BK, McEvoy CT. Trajectories of lung function in infants and children: setting a course for lifelong lung health. Pediatrics. (2020) 146:e20200417. doi: 10.1542/peds.2020-0417

28. Satrell E, Røksund O, Thorsen E, Halvorsen T. Pulmonary gas transfer in children and adolescents born extremely preterm. Eur Respir J. (2013) 42:1536-44. doi: 10.1183/09031936.00027112

29. Thibeault DW, Mabry SM, Norberg M, Truog WE, Ekekezie II. Lung microvascular adaptation in infants with chronic lung disease. Biol Neonate. (2004) 85:273-82. doi: 10.1159/000076388

30. Bhatt AJ, Pryhuber GS, Huyck H, Watkins RH, Metlay LA, Maniscalco WM. Disrupted pulmonary vasculature and decreased vascular endothelial growth factor, flt-1, and tie-2 in human infants dying with bronchopulmonary dysplasia. Am J Respir Crit Care Med. (2001) 164:1971-80. doi: 10.1164/ajrccm.164.10.2101140 
31. Hakulinen AL, Jarvenpaa A, Turpeinen M, Sovijarvi A. Diffusing capacity of the lung in school-aged children born very preterm, with and without bronchopulmonary dysplasia. Pediatr Pulmonol. (1996) 360:353-60.

32. Welsh L, Kirkby J, Lum S, Odendaal D, Marlow N, Derrick G, et al. EPICure Study Group. The EPICure study: maximal exercise and physical activity in school children born extremely preterm. Thorax. (2010) 65:16571. doi: 10.1136/thx.2008.107474

33. Lum S, Kirkby J, Welsh L, Marlow N, Hennessy E, Stocks J. Nature and severity of lung function abnormalities in extremely pre-term children at 11 years of age. Eur Respir J. (2011) 37:1199-207. doi: 10.1183/09031936.000 71110

34. Um-Bergström P, Hallberg J, Pourbazargan M, Berggren-Broström E, Ferrara G, Eriksson MJ, et al. Pulmonary outcomes in adults with a history of Bronchopulmonary Dysplasia differ from patients with asthma. Respir Res. (2019) 20:102. doi: 10.1186/s12931-019-1075-1

35. Sørensen JK, Buchvald F, Berg AK, Robinson PD, Nielsen KG. Ventilation inhomogeneity and NO and CO diffusing capacity in ex-premature school children. Respir Med. (2018) 140:94-100. doi: 10.1016/j.rmed.2018.06.006

36. Course CW, Kotecha S, Kotecha SJ. Fractional exhaled nitric oxide in pretermborn subjects: a systematic review and meta-analysis. Pediatr Pulmonol. (2019) 54:595-601. doi: 10.1002/ppul.24270
37. McGrath-Morrow SA, Collaco JM. Bronchopulmonary dysplasia: what are its links to COPD? Ther Adv Respir Dis. (2019) 13:1753466619892492. doi: 10.1177/1753466619892492

38. Allen J, Zwerdling R, Ehrenkranz R, Gaultier C, Geggel R, Greenough A, et al. American Thoracic Society. Statement on the care of the child with chronic lung disease of infancy and childhood. Am J Respir Crit Care Med. (2003) 168:356-96. doi: 10.1164/rccm.168.3.356

39. Baraldi E, Filippone M. Chronic lung disease after premature birth. N Engl J Med. (2007) 358:743-6. doi: 10.1056/NEJMc073362

Conflict of Interest: The authors declare that the research was conducted in the absence of any commercial or financial relationships that could be construed as a potential conflict of interest.

Copyright (c) 2021 Di Filippo, Giannini, Attanasi, Dodi, Scaparrotta, Petrosino, Di Pillo and Chiarelli. This is an open-access article distributed under the terms of the Creative Commons Attribution License (CC BY). The use, distribution or reproduction in other forums is permitted, provided the original author $(s)$ and the copyright owner(s) are credited and that the original publication in this journal is cited, in accordance with accepted academic practice. No use, distribution or reproduction is permitted which does not comply with these terms. 